\title{
Triple-Indicator-Based Multidimensional Colorimetric Sensing Platform for Heavy Metal Ions Detections
}

\author{
Noorhayati Idros ${ }^{1,2}$, Daping $\mathrm{Chu}^{1 *}$ \\ ${ }^{1}$ Centre for Photonic Devices and Sensors, Department of Engineering, University of Cambridge, Cambridge, \\ CB3 0FA, United Kingdom \\ ${ }^{2}$ Institute of Nano Electronic Engineering, Universiti Malaysia Perlis, Lot 106, 108 \& 110, Tingkat 1, Block A, \\ Taman Pertiwi Indah, Jalan Kangar-Alor Setar, Seriab, 01000 Kangar, Perlis, Malaysia
}

KEYWORDS: paper-based microfluidics, triple indicator, heavy metals, colour calibration, multidimensional sensing.

\begin{abstract}
Heavy metals are highly toxic at trace levels and their pollution has shown great threat to the environment and public health worldwide where current detection methods require expensive instrumentation and laborious operation, which can only be accomplished in centralized laboratories. Herein, we report a low-cost, paper-based microfluidic analytical device ( $\mu$ PAD) for a facile, portable and disposable monitoring of mercury, lead, chromium, nickel, copper and iron ions. Triple indicators or ligands that contain ions or molecules are preloaded on the $\mu$ PADs and upon addition of a metal ion, the colorimetric indicators will elicit colour changes observed by the naked eyes. The colour features were quantitatively analysed in a three-dimensional space of red, green and blue or the RGB-space using digital imaging and colour calibration techniques. The sensing platform offers higher accuracy for cross references, and is capable of simultaneous detection and discrimination of different metal ions in even real water samples. It demonstrates great potential for semi-quantitative and even qualitative analysis with a sensitivity below the safe limit concentrations, and a controlled error range.
\end{abstract}

Heavy or transitional metals are normally defined as elements with a specific density above $5 \mathrm{~g} \mathrm{~cm}^{-3}{ }^{1}$ and is one that forms one or more stable ions which have incompletely filled d orbitals. Many of the transitional metal ions act as Lewis acids (electron pair acceptors) as they contain empty valence orbitals. Some metals are essential for life, such as zinc and magnesium, and are naturally available in food and water. However, high exposure to heavy metals may cause chronic or acute poisoning. Heavy metals such as lead, chromium, copper, and mercury are highly toxic even at trace levels. They damage or reduce mental and central nervous functions and affect blood composition, lungs, kidneys, liver, and other vital organs. ${ }^{2,3}$

Pollution of water resources by heavy metals, occurring largely due to human activities such as battery and pesticide manufactures, and metal plating have profoundly influenced global water resources to the critical water supply and drinking water quality in recent years. It is recognized that 1.6 million children die each year, for which contaminated drinking water is a leading cause. ${ }^{1}$ Therefore, it is highly desirable to develop a reliable, low-cost and sustainable environmental monitoring so that contamination can be detected in the relevant systems.

A wide variety of instrumental methods have been developed for determining environmental heavy metals. Current sophisticated analytical techniques include: (a) inductively coupled plasma/mass spectrometry, (b) inductively-coupled plasma-atomic/optical emission spectrometry, (c) energy dispersive X-ray fluorescence, (d) atomic absorption spectrometry, (d) atomic emission spectrometry, (e) UV-VIS spectroscopy, and (f) anodic stripping voltammetry. ${ }^{4-7}$ These laboratory-based techniques are highly sensitive in concentrations as low as one part per trillion, ${ }^{2,8}$ specific, and accurate for monitoring trace amounts of heavy metals in the environment. However, they require tedious sample preparation and pre-concentration procedures, involve time-consuming and laborious procedures that can be carried out only by trained professionals, as well as requiring expensive, bulky and complex instrumentation. ${ }^{9-10}$ Moreover, they cannot be used as portable devices for on-site detection.

Colorimetric sensors, in contrast, show great potential for high throughput detection of heavy metals on-site. They are one of the most commonly used approaches for laboratory tests and industrial applications, such as the detection of heavy metals in wastewater. ${ }^{11}$ In recent years, a multidimensional sensing approach has attracted many researchers to construct sensing systems that involve a sensor array by merging a selection of cross-reactively colorimetric indicators ${ }^{12-23}$ with lab-on-amolecule/nanoparticles by integrating fluorescent, phosphorescent, light-scattering, absorbing, and/or electrochemiluminescent (ECL) reporters on a molecule or a nanoparticle ${ }^{24-32}$; and a smart chip which mechanically 
incorporates calorimetric, capacitive and mass-sensitive transducers. ${ }^{33-35}$ However, these approaches are limited in their potential uses because they require complicated synthesis, fabrication processes or need a variety of instruments and techniques to attain sensing signals.

For example, Song et al. ${ }^{36,37}$ designed and fabricated microchips for the recognition of metal ions based on a single indicator via multiple fluorescent channels, and Leng et al. ${ }^{38}$ constructed multidimensional sensing platforms based on a single indicator

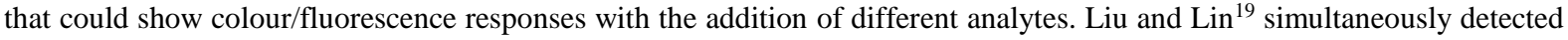
multiple heavy metal ions using a paper-based colorimetric array test strip. These examples involve complicated synthesis and experimental setups that have inspired efforts to develop a simpler, inexpensive approach incorporating specific indicators that show discrete colour responses to different analytes. ${ }^{36,37,39-46}$

To prepare a much low-cost and simpler technique, we employed a metal-ligand coordination chemistry to form coloured coordination complexes that can be observed by the naked eyes with an integration of paper-based microfluidics, $\mu$ PADs, technology. The $\mu \mathrm{PADs}$ technology has established a reputation for cost-effectiveness, rapid results, high sensitivity, specificity, and accuracy and rapidly developed as colorimetric sensors for detection of a broad range of targets. Yamada et al. ${ }^{47}$ reported a urinary protein sensor in the form of a versatile text-displaying mechanism based on printing techniques as simple as wax printing, to inkjet printing and 3D printing, whilst Chan et al ${ }^{48}$ developed a urinary protein sensor using movable and user-friendly 3D printed microfluidic components which include torque-actuated pump and valve, rotary valve, and pushing valve which can be operated manually with a smartphone as the imaging platform.

Although detection of heavy metal ions (HMIs) using $\mu$ PADs is still in its immaturity, the first successive use of $\mu$ PADs was in $2011^{49}$, the technology has been rapidly applied to detect a broad range of heavy metal ions and with the integration of the $3 \mathrm{D}$ paper-based technology system, colorimetric verification, and an application of a camera as detector ${ }^{50}, \mu \mathrm{PADs}$ are considered to be promising candidates for the environmental monitoring of heavy metal ions.

Sun et al. ${ }^{51}$ developed a suspending-droplet mode $\mu$ PADs using surface tension and gravity to actuate droplets. The device is coupled with a G-quadruplex based luminescence switch-on assay for sensing lead (II) ions. A paper-based 3D microfluidic device for monitoring heavy metals was also reported by Wang et al..$^{50}$ The device was developed by stacking layers of wax patterned paper and double sided adhesive tape with the incorporation of a smart phone camera. The technique is suitable for on-site testing of copper, nickel, cadmium, and chromium ions because of its portability and capability of wicking and distribute fluids without external pumps. Hossain and Brennan ${ }^{49}$ developed a rapid and sensitive $\beta$-galactosidase (B-GAL)based colorimetric paper sensor, fabricated by inkjet printing of sol-gel based bioinks for determination of single and mixed heavy metal ions without the need of external instrumentation. A low-cost, portable and lightweight colorimetric-based $\mu$ PADs developed by $\mathrm{Li}$ and coworkers ${ }^{52}$ operates based on light reflectance signal which can be attained directly, stably, and userfriendly for detection of BSA, glucose, iron(II), and nitrite.

Chaiyo, Apiluk, Siangproh and Chailapakul ${ }^{53}$ developed $\mu$ PADs coupled with dual electrochemical and colorimetric sensor using a bismuth-modified, boron-doped diamond electrode (Bi-BDDE) and silver nanoplates (AgNPls), respectively for detection of lead, cadmium and copper. Monitoring of copper, nickel and chromium using a 'periodic-table-style' $\mu$ PADs were developed by Li et al. ${ }^{54}$ by printing indicators in chemical symbols of the metals in a style of the periodic table of elements. The text-reporting device provides easy solutions to field-based monitoring of HMIs and requires nonprofessional users to analyse the results. $\mu$ PADs developed by Meelapsom et al. ${ }^{55}$ utilized alkyl ketene dimer (AKD)-inkjet printing and doped with unmodified silver nanoparticles (AgNPs) which were disintegrated when being exposed to mercury(II). The color intensity was detected by using an apparatus consisting of a digital camera and a homemade light box generating constant light intensity.

This article reports a triple-based indicator multidimensional colorimetric platform with integration of $\mu$ PADs for detection of single and mixed HMIs. Colour calibration (CC) is performed to quantify the colour differences between different ligands to similar metal, and a similar ligand to different metals reactions as illustrated in Table S-1 in the Supporting Information, without the need of complicated synthesis or experimental setups. The CC method provides semi-quantitative readouts with the aid of a calibration chart. A simple wax stamping method using a handheld and lightweight metal stamp is exploited to fabricate the $\mu$ PADs. Multiple ligands are then preloaded on the $\mu$ PADs and once the heavy metal is loaded and distributed over different channels, chemical reactions take place between the ligands and the target analytes that allow for visual determination of the target analytes through the colour changes in the detection zones.

This proof-of-concept device uses a wholly novel approach. By using three types of indicator or ligand, rather than just one, cross referencing increases the accuracy. By using multidimensional colorimetric sensing, strong colour contrasts can be detectable by the naked eye, though very similar cases require more sophisticated analytical techniques, such as digital imaging. By incorporating a sophisticated multidimensional colorimetric analysis with a simple fabrication technique of the $\mu$ PADs makes the device inexpensive, biodegradable, lightweight, portable, and suitable for rapid on-site detections. The proposed devices were successfully applied to simultaneous determination of $\mathrm{Hg}^{2+}, \mathrm{Pb}^{2+}, \mathrm{Cr}^{2+}, \mathrm{Ni}^{2+}, \mathrm{Cu}^{2+}$ and $\mathrm{Fe}^{3+}$, and discrimination of different metal ions in a mixed solution of $\mathrm{Cr}^{2+}, \mathrm{Cu}^{2+}$ and $\mathrm{Fe}^{3+}$ in real samples. 



\section{EXPERIMENTAL SECTION}

Materials and Methods. The ligands/indicators used in this experiment include tetrakis(4-carboxyphenyl)porphyrin (TCPP), amine of (3-aminopropyl)triethoxysilane $\left(-\mathrm{NH}_{2}\right)$, toluene $(\mathrm{MePh})$, sodium iodide $(\mathrm{NaI})$, potassium iodide $(\mathrm{KI})$ and $\left(\mathrm{C}_{6} \mathrm{H}_{4}\left(\mathrm{NH}_{2}\right)_{2}\right)$ 1,2-phenylenediamine (12P). Copper $\left(\mathrm{Cu}^{2+}\right)$, iron $\left(\mathrm{Fe}^{3+}\right)$, nickel $\left(\mathrm{Ni}^{2+}\right)$, chromium $\left(\mathrm{Cr}^{2+}\right)$, mercury $\left(\mathrm{Hg}^{2+}\right)$, and lead $\left(\mathrm{Pb}^{2+}\right)$ ions were prepared from their metal salt in aqueous solution purchased from Sigma-Aldrich. Whatman ${ }^{\circledR}$ qualitative filter paper Grades 1 and 4, and commercial candles were used to create $\mu$ PADs hydrophobic barriers using a wax stamping method and a metal stamp. A calibration reference of Munsell colorchecker 24 charts, and MATLAB Image Processing Tools were employed to execute the color calibration algorithm.

Choice of Paper. The performance of Whatman ${ }^{\circledR}$ qualitative filter paper, Grades 1 and 4 were studied. Their performance was examined in terms of: (a) volume of indicators, (b) reaction colour quality between the indicator and the HMIs, and (c) the microfluidic channel resolution. 5 out of 6 uniform $\mathrm{Cu}^{2+}$ complexes colour reproduced using Grade 1 with a binding time twice as fast as Grade 4 paper and 50\% smaller wax diffusion rings observed at 2 seconds stamping time. Section 6 in the Supporting Information explains the characteristic of the paper in detail.

Fabrication of $\boldsymbol{\mu P A D s}$. A handheld and lightweight stamp was utilised to transfer the microfluidics pattern onto paper. To fabricate the metal stamp, layout of the microfluidic structure was machined on a stainless-steel surface and subsequently used for rapid prototyping of $\mu$ PADs, motivated by the method implemented by Garcia et. al. ${ }^{58}$ Candles were melted at $130^{\circ} \mathrm{C}$ on a hot plate prior to wax stamping. Grade 1 paper was subsequently soaked in the melted wax for $10 \mathrm{~s}$ and cooled down to ambient temperature. The 'waxed paper' was then placed onto a fresh paper of similar grade, ready for stamping. A stainless-steel stamp was heated up to $130^{\circ} \mathrm{C}$ for $2 \mathrm{~min}$ on a hot plate. The hot stamp was positioned in contact with the previously waxed paper for $2 \mathrm{~min}$. The direct contact allowed for the transfer of an amount of wax to a fresh paper located below the waxed piece, thus creating hydrophobic barriers with great reproducibility by a single stamping process. The $\mu$ PADs dimensions: channel width $=3 \mathrm{~mm}$, channel length $=5 \mathrm{~mm}$, detection zone diameter $5 \mathrm{~mm}$, and target zone diameter $=10 \mathrm{~mm}$ as depicted in Figure S-7 of the Supporting Information.

Digital Imaging. Nikon D7000 camera with setting of f-number 5.6 and ISO 2000 was applied together with illumination and viewing geometry of approximately $45 / 0^{\circ}$. In this viewing geometry, the sample was illuminated with beam of light incident at an angle of about $45^{\circ}$ and measurement were made along the normal. The imaging system was installed in a darkroom. Incandescent (I), fluorescent (F), LED (L) and daylight (D) lighting conditions were tested.

Colour Calibration. The colour calibration scheme contains three main steps: (a) selection of sRGB target deviceindependent colour space, (b) application of polynomial-based algorithms using a 24-patch Macbeth colorchecker as reference, and (c) evaluation of the algorithm performance by taking their average root mean square (RMS) values. The reference target of Munsell Colorchecker ${ }^{59}$ contains 24 colour patches was printed on a piece of A4 paper and was used to train the parameters for the calibration model. After the HMI detection was done using $\mu$ PADs, the device was pasted onto the A4 paper which consisted of the 24-patches colorchecker. MATLAB Image Processing Tools were employed to run several polynomial-based algorithms for the colour calibration process. First, the captured colorchecker was corrected to the sRGB values ${ }^{59}$ of the reference, as demonstrated in Figure 1 (a) which subsequently automatically calibrated the captured image of the $\mathrm{Cu}^{2+} \mu \mathrm{PADs}$ under fluorescent light as seen in Figure 1 (b). Figure 1 (c) illustrates the triple indicators that were used to detect $\mathrm{Cu}^{2+}$ simultaneously on one part of the detection pad.

(a)

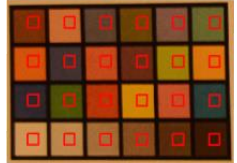

Captured

(b)

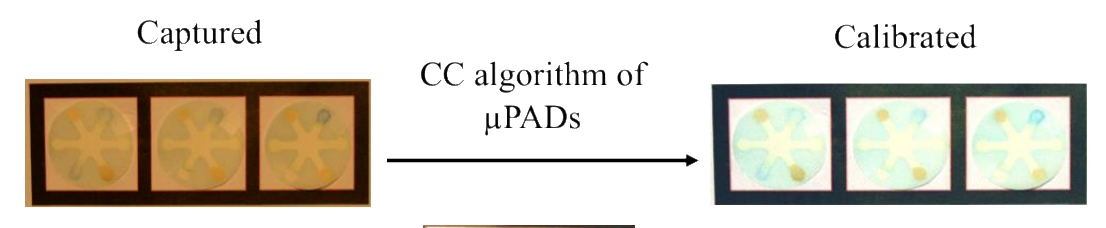

(c)

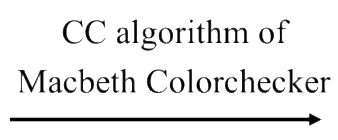

(c)

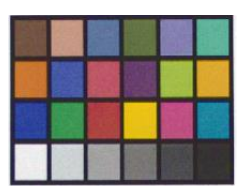

Toluene (MePh)

Amine $\left(-\mathrm{NH}_{2}\right)$

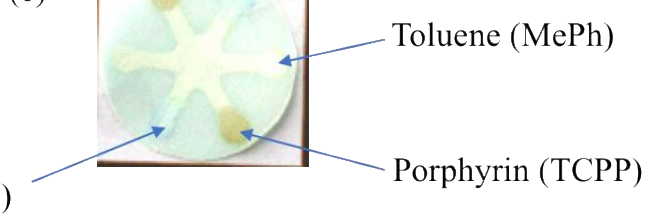

Figure 1. Colour calibration process under fluorescent light: (a) Macbeth Colorchecker, (b) its RGB values were extracted from 50x50 pixels which then used to calibrate the (c) copper ions $\mu \mathrm{PAD}$ and multiple indicators used. 



\section{RESULTS AND DISCUSSION}

Paper Selection. Grade 1 paper was selected for fabrication of $\mu$ PADs due to its paramount properties; smooth and uniform surface on both sides, medium flow rate, and $0.18 \mathrm{~mm}$ thickness that permits printing in commercial machines. It is important to highlight that Grade 1 paper consists of $98 \% \alpha$-cellulose, with no additives used such as instance strengthening or whitening agents, thus reducing the possibility of interference. ${ }^{60-62}$

Colour Calibration. First- and second-order polynomial algorithms were tested. The latter demonstrates smaller average RMS values for both calibrated Munsell colorchecker and HMIs $\mu$ PADs images. Therefore, the algorithm was utilized to first calibrate the captured colorchecker images under four ambient lighting conditions and uniform calibrated images are observed in Figure 2. Similarly, Figure 3 (b) illustrates uniform calibrated images of $\mu$ PADs for six single HMIs. The average RGB values $(0-255)$ of the calibrated $\mu$ PADs were extracted and presented in a three-dimensional, 3D, RGB colour matrix of single HMIs at 0.1 M illustrated in Figure 4. Thus far, a proof-of-concept device using a wholly novel approach has been successfully calibrated in the 3D space. By averaging the RGB values of the lighting conditions, the 3D-RGB plot indicates eminent RGB separation for different indicators which demonstrates the selectivity of the sensor. The RGB separation of these HMIs in their wastewater discharge concentrations were further examined and their linear responses are plotted in Figure 5.

(a)
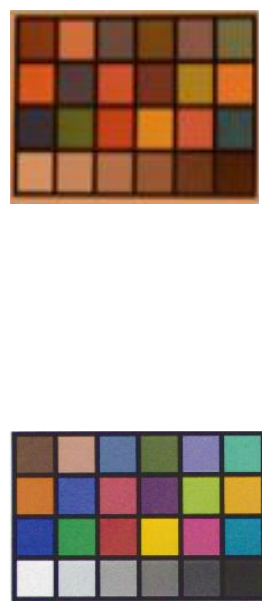

$\mathrm{F}$

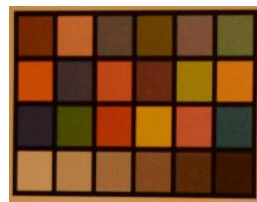

$\mathrm{L}$

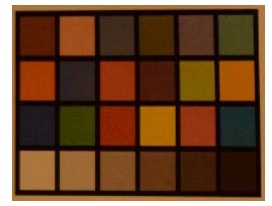

\section{Color Calibration}

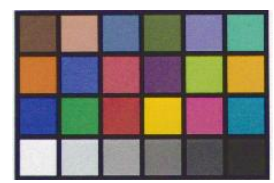

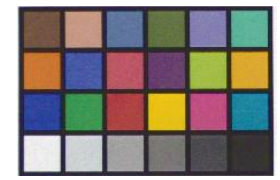

$\mathrm{D}$
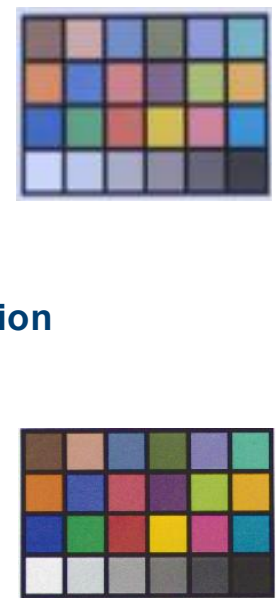

Figure 2. Colour calibration of the colorchecker under ambient lighting conditions: (a) captured and (b) calibrated images. Incandescent (I), fluorescent (F), LED (L) and daylight (D) lighting conditions were tested.

Heavy Metal Complexes Color. A coloured complex form when a heavy or transitional metal ion accepts electron pairs situated in the centre of the indicator resulting in electron transfer between split $d$ orbitals. If no $d$ electrons are present, no electron transfer can occur, and the compounds are not coloured. The colour of the compounds is also related to the magnitude of $\Delta$ (the $d$-orbital splitting value). The energy split is measured by locating the maximum or peak wavelength, $\lambda_{\max }$, of the UV-vis absorption spectrum, which indicates the amount of energy needed to excite an electron from the ground state (HOMO) to the excited state (LUMO) of the metal-indicator complexes. The strongest-field indicator produces the greatest $d$-orbital splitting (largest $\Delta$ ) because of the lack of unpaired electrons and will absorb light having the smallest wavelength. Weak-field compounds will have the smallest $\Delta$ (with unpaired electrons present), so the wavelength of light absorbed will be longest because energy and wavelength are inversely related: $\lambda=h c / E$, where $\lambda$ is the electromagnetic wavelength (nm), $h$ is the plank constant, $c$ is the speed of light, and E is energy. ${ }^{63-64}$ The energy gaps of $\pi-\pi^{*}$ transitions in HMIs-TCPP complexes are smaller than other indicators, thus, the wavelength absorbed is longer. This is because when a conjugated molecular ring system (macrocycles) such as porphyrin absorbs light, it undergoes a $\pi-\pi^{*}$ transition. Because $\pi-\pi^{*}$ energy gaps are narrower than $\sigma-\sigma^{*}$ gaps, a $\mathrm{Cu}^{2+}-\mathrm{TCPP}$ complex absorbs light at $428 \mathrm{~nm}-$ a longer wavelength than $\mathrm{Cu}^{2+}-\mathrm{NH}_{2}$ at $319 \mathrm{~nm}$. As conjugated pi systems become larger, the energy gap, $\Delta \mathrm{E}$, for the $\pi-\pi^{*}$ transition becomes increasingly narrow, and correspondingly the wavelength of light absorbed becomes longer. For example, the absorbance due to the $\pi-\pi^{*}$ transition as the HMI-TCPP complexes get larger from $\mathrm{Pb}^{2+}, \mathrm{Cu}^{2+}, \mathrm{Fe}^{3+}, \mathrm{Cr}^{2+}, \mathrm{Hg}^{2+}$, to $\mathrm{Ni}^{2+}$, occurs at 423, 428, 451, 453, 458, to $458 \mathrm{~nm}$, corresponding to a narrower $\Delta \mathrm{E}$ of $2.93,2.89,2.74,2.73,2.70$, to $2.70 \mathrm{eV}$, respectively. A similar concept is observed for the $\sigma-\sigma^{*} \mathrm{HMI}$ complexes formed with $-\mathrm{NH}_{2}$ and third indicators and provided in the supporting document. 


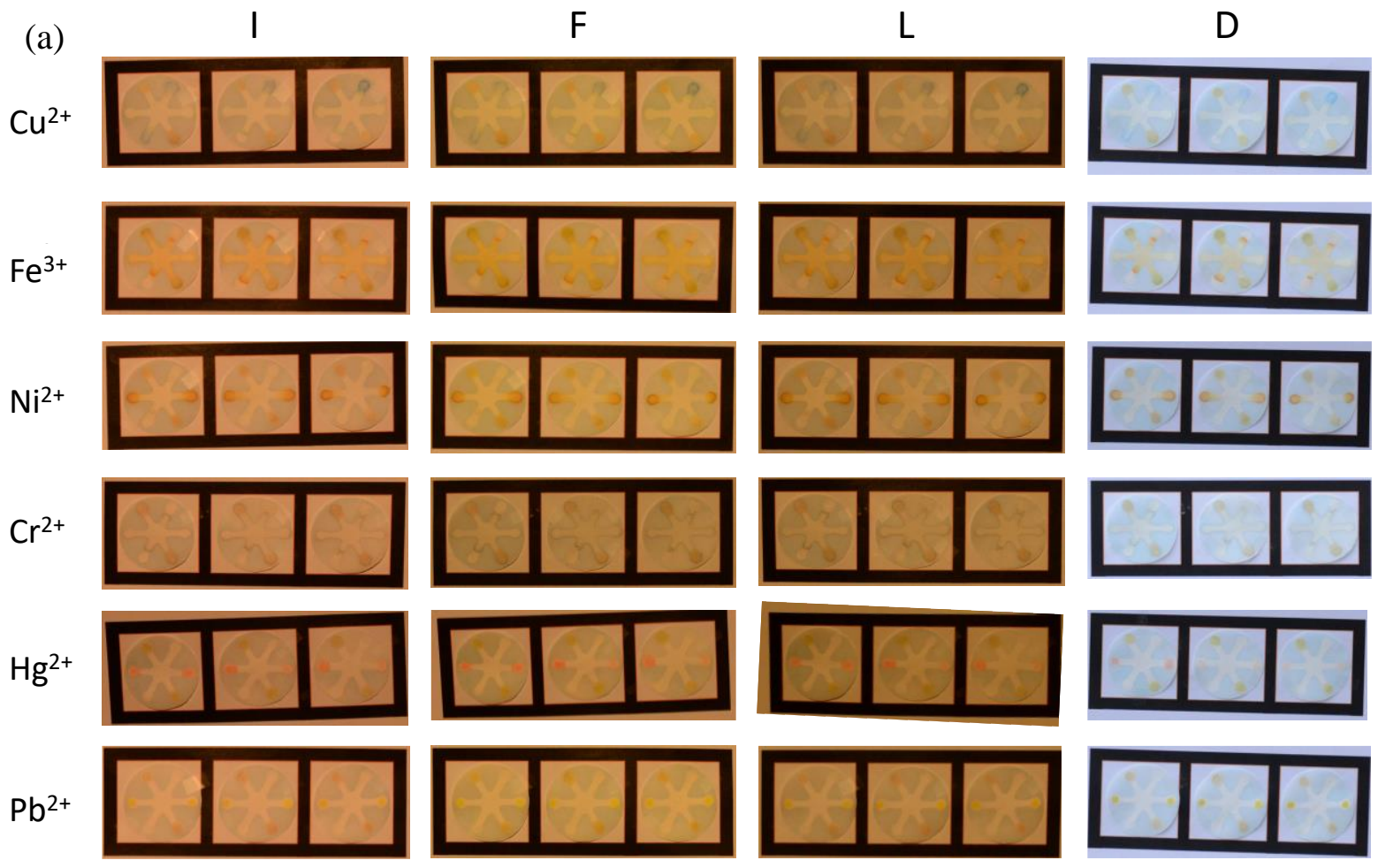

(b)

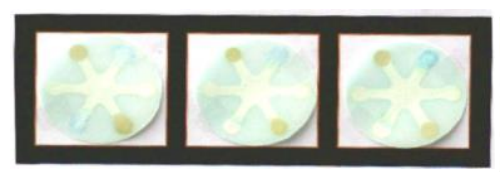

$\mathrm{Cu}^{2+}$

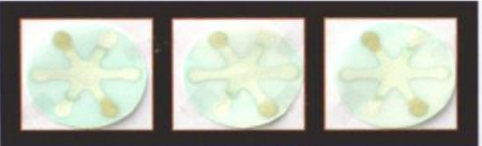

$\mathrm{Cr}^{2+}$

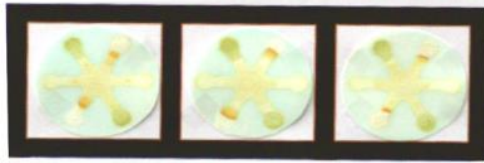

$\mathrm{Fe}^{3+}$

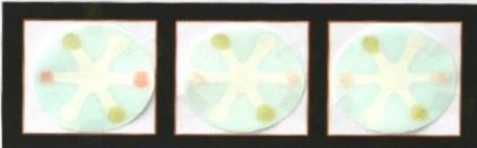

$\mathrm{Hg}^{2+}$

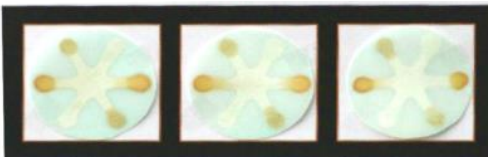

$\mathrm{Ni}^{2+}$

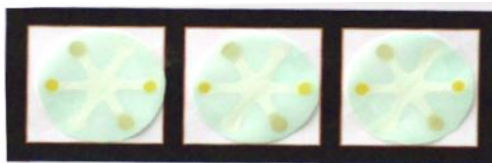

$\mathrm{Pb}^{2+}$

(c)

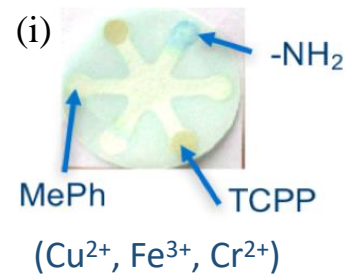

(ii)

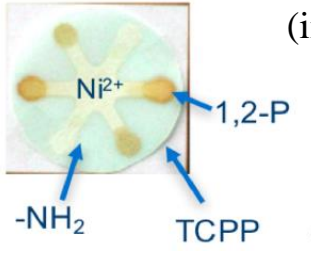

(iii)

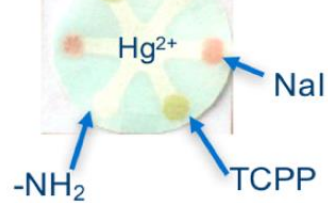

(iv)

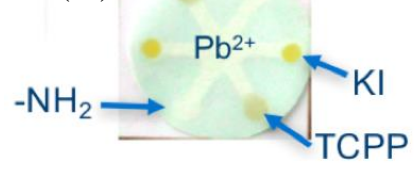

Figure 3: Colour calibration of the $\mu$ PADs under ambient lighting conditions: (a) captured, (b) calibrated images and (c) the reactions of metal ions (i) $\mathrm{Cu}^{2+}, \mathrm{Fe}^{3+}, \mathrm{Cr}^{2+}$, (ii) $\mathrm{Ni}^{2+}$, (iii) $\mathrm{Hg}^{2+}$, and (iv) $\mathrm{Pb}^{2+}$ with their respective ligands. 

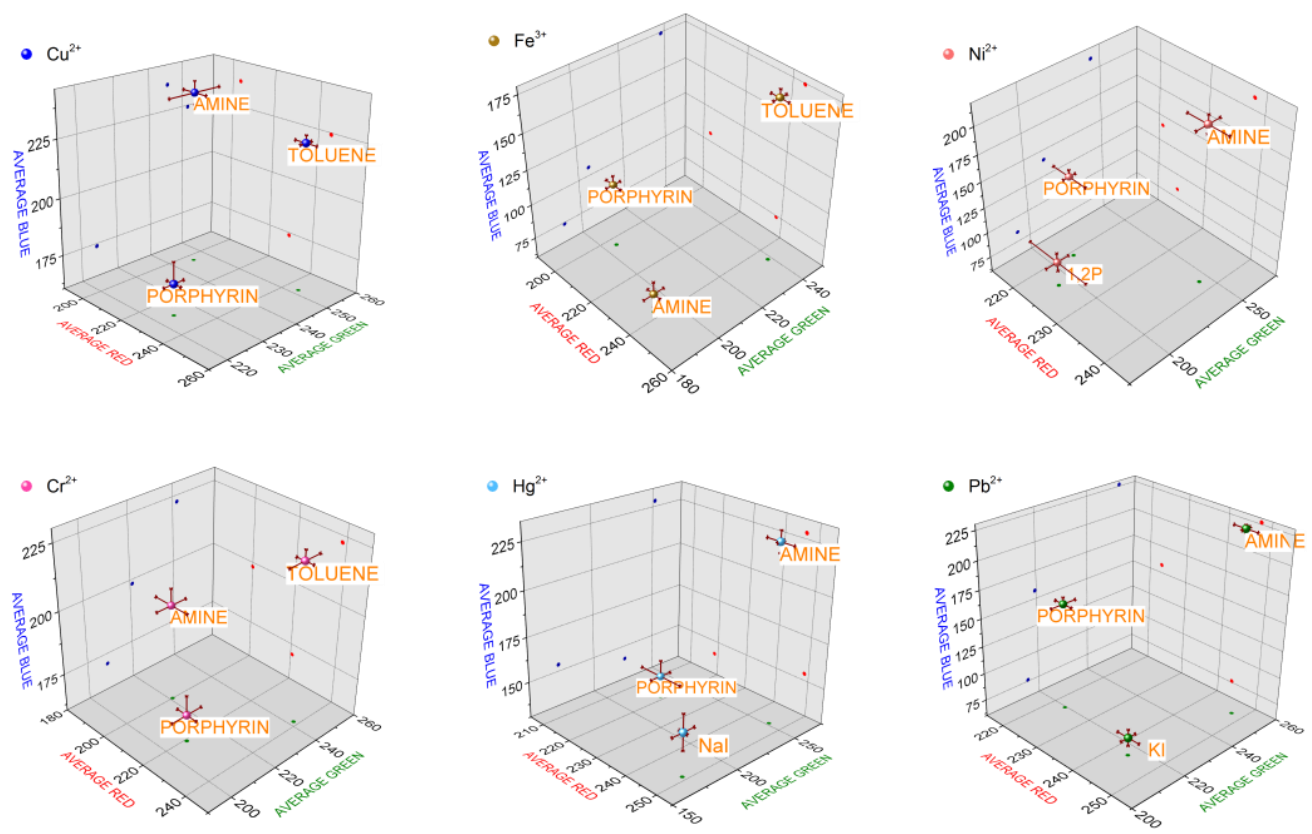

Figure 4. The calibrated 3D RGB colour matrix of single HMIs at $0.1 \mathrm{M}$.

Wastewater Discharge Concentrations. The RGB profiles of the single HMI interactions with multiple indicators at their wastewater discharge concentrations were studied. When the single HMIs were made to chelate with TCPP, most produced a very similar colour when observed with the naked eye. However, the use of digital imaging and the colour calibration method means that their colour profiles can be analyzed and be seen to increase with their increasing concentration. This showed that TCPP is a universal indicator which can be used to capture almost any metals, regardless of their size. When the HMIs are made to chelate with a second indicator $-\mathrm{NH}_{2}$, and some third indicators, a group of HMIs such as $\mathrm{Pb}^{2+}, \mathrm{Hg}^{2+}$ and $\mathrm{Ni}^{2+}$, and $\mathrm{Cr}^{2+}, \mathrm{Fe}^{3+}$ and $\mathrm{Cu}^{2+}$ formed white precipitates and/or experienced no colour change, which resulted in the saturated RGB values. They behave as a sensor control, which adds a discrimination capability to the sensing system.

The Euclidean distances (EDs) were calculated taking the RGBs of "before" and "after" colour changes as a result of the formation of metal complexes. A linear composition taking 0.33 weightage of each indicator ED response using Equation (1) was successfully optimized, as shown in Figure 5. The multiple indicator based multidimensional sensing demonstrates good linearity for $\mathrm{Cr}^{2+}$, and $\mathrm{Fe}^{2+}$ over the whole composition range and detection limit, below their safe limit and wastewater discharge concentrations.

$$
\text { Response }=0.33 *\left(\text { Ligand }_{1}+\text { Ligand }_{2}+\text { Ligand }_{3}\right)
$$

According to the linear composition of HMIs plot and Table 1, the limit of detections (LOD) of $\mathrm{Cu}^{2+}$ and $\mathrm{Ni}^{2+}$ are $15 \mu \mathrm{M}$ and $0.5 \mu \mathrm{M}$ which are below their safe limits of 20.46 and $1.19 \mu \mathrm{M}$ respectively. Though the $\mathrm{Hg}^{2+} \mathrm{LOD}$ of $0.1 \mu \mathrm{M}$ is higher than its safe limit value by twenty times, but the response is comparable to the findings reported by Leng et al. ${ }^{38}$ and two and a half times more sensitive than Liu and $\mathrm{Lin}^{19}$ having a much simpler and cheaper approach. The LOD of $\mathrm{Pb}^{2+}$ is observed at $0.3 \mu \mathrm{M}$.

The sensor demonstrates its capability to detect $\mathrm{Cr}^{2+}, \mathrm{Fe}^{2+}, \mathrm{Cu}^{2+}$ and $\mathrm{Ni}^{2+}$ below their safe limit concentrations, with the advantages in terms of simplicity, cost, disposability and portability. Its capability was further tested to identify ions composition in a mixture. Figure 6 illustrates the calibrated images of $\mathrm{Cu}^{2+}, \mathrm{Cr}^{2+}$, and $\mathrm{Fe}^{3+}$ mixture with different mixing ratios. The $\left(\mathrm{Cu}^{2+}, \mathrm{Cr}^{2+}, \mathrm{Fe}^{3+}\right)$ mixing ratios are $(\mathrm{a})=(0,1 / 3,2 / 3),(\mathrm{b})=(0,2 / 3,1 / 3),(\mathrm{c})=(1 / 3,0,2 / 3),(\mathrm{d})=(2 / 3,0,1 / 3),(\mathrm{e})=(2 / 3$, $1 / 3,0),(\mathrm{f})=(1 / 3,2 / 3,0)$, and $(\mathrm{g})=(1 / 3,1 / 3,1 / 3)$. By calculating the EDs of the coefficient coordinates between mixed and non-mixed solutions, a reliable determination of ions is achieved for all mixing ratios except for the cases of a and $\mathrm{c}$. This may be supported by the strong absorption of visible light by $\mathrm{Fe}^{3+}$ (see Figure $\mathrm{S}-1$ and S-2, and Table S-4 of the supporting document) which dominates the resultant colour of the 'mixed' complexes. Both $\mathrm{Cr}^{2+}$ and $\mathrm{Fe}^{3+}$ absorbed light at around 450 $\mathrm{nm}$ after forming complexes with $-\mathrm{NH}_{2}$. This produced yellow complexes that can be perceived in Figure 6 (a) (L2) by the naked eyes. There is no absorption of visible light from $\mathrm{Cu}^{2+}-\mathrm{NH}_{2}$ complex while $\mathrm{Fe}^{3+}-\mathrm{NH}_{2}$ complex has an absorption maximum between $400-450 \mathrm{~nm}$. Therefore, green-yellow precipitates can be observed by the naked eyes as shown in Figure 6 (c) (L2). To further investigate, it may be helpful to extend the illumination and detection range to infra-red and even to ultra-violet wavelengths. 

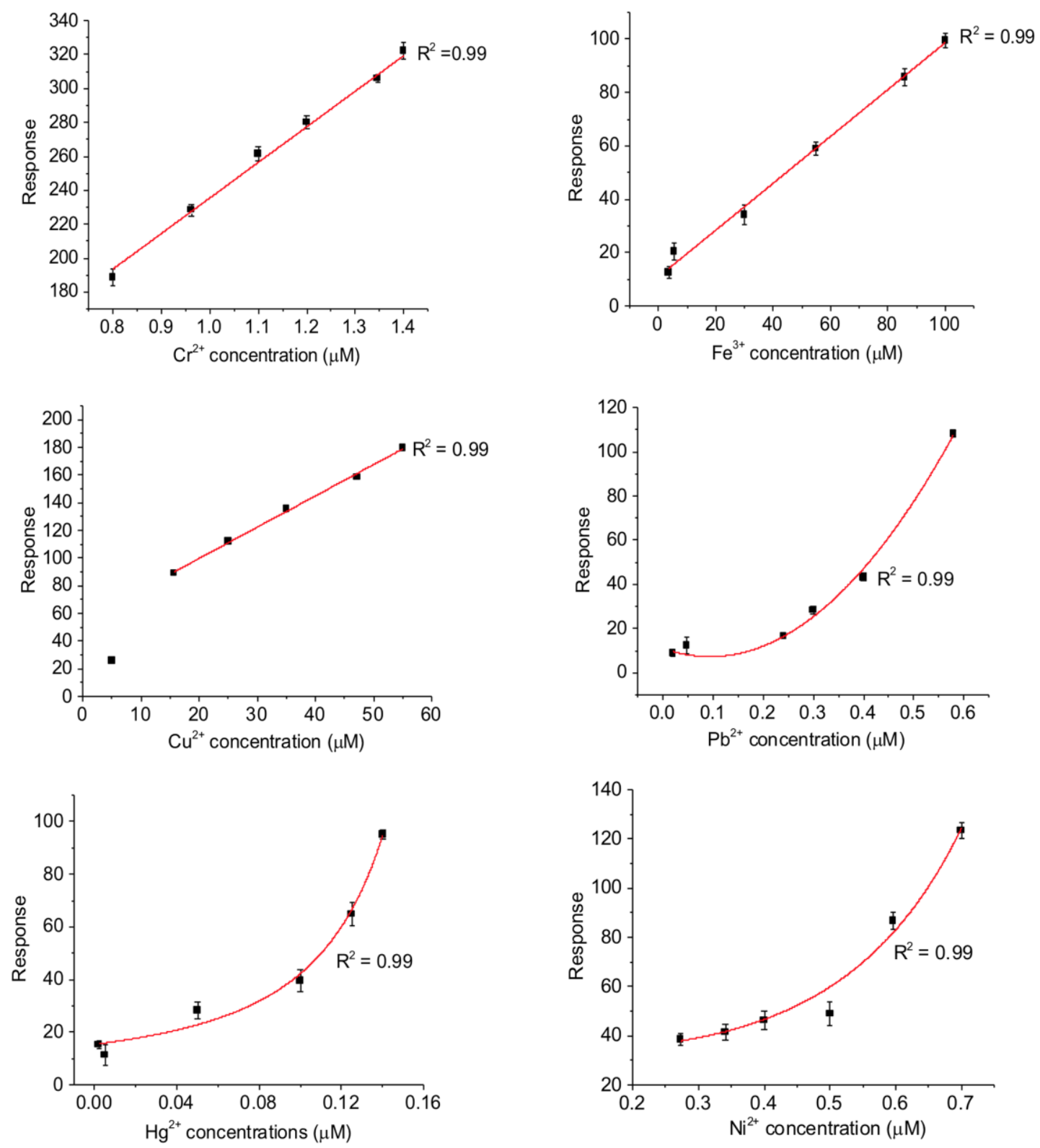

Figure 5. Linear responses of HMIs at wastewater discharge concentrations.

Table 1. Sensor's detection limit concentration, the heavy metals equivalent safe limit and multiple ligands used.

\begin{tabular}{cccl}
\hline $\begin{array}{c}\text { Heavy } \\
\text { metal } \\
\text { ions }\end{array}$ & $\begin{array}{c}\text { Detection } \\
\text { limit } \\
\text { concentration }\end{array}$ & $\begin{array}{c}\text { Safe limit } \\
\text { concentration }\end{array}$ & Ligands \\
\hline $\mathrm{Cu}^{2+}$ & $15 \mu \mathrm{M}$ & $\begin{array}{c}20.46 \mu \mathrm{M} \\
(1300 \mu \mathrm{g} / \mathrm{L})^{56}\end{array}$ & $\mathrm{TCPP},-\mathrm{NH}_{2}, \mathrm{MePh}$ \\
& & $\begin{array}{c}5.37 \mu \mathrm{M} \\
\mathrm{Fe}^{3+}\end{array}$ & $\mathrm{TCPP},-\mathrm{NH}_{2}, \mathrm{MePh}$ \\
& $3.58 \mu \mathrm{M}$ & $(300 \mu \mathrm{g} / \mathrm{L})^{56}$ & \\
$\mathrm{Ni}^{2+}$ & $0.5 \mu \mathrm{M}$ & $1.19 \mu \mathrm{M}$ & $\mathrm{TCPP},-\mathrm{NH}_{2}, 12 \mathrm{P}$ \\
& & $(70 \mu \mathrm{g} / \mathrm{L})^{57}$ & \\
$\mathrm{Cr}^{2+}$ & $0.8 \mu \mathrm{M}$ & $1.92 \mu \mathrm{M}$ & $\mathrm{TCPP},-\mathrm{NH}_{2}, \mathrm{MePh}$ \\
& & $(100 \mu \mathrm{g} / \mathrm{L})^{56}$ & \\
$\mathrm{Hg}^{2+}$ & $0.1 \mu \mathrm{M}$ & $10 \mathrm{nM}$ & $\mathrm{TCPP},-\mathrm{NH}_{2}, \mathrm{NaI}$ \\
& & $(2 \mu \mathrm{g} / \mathrm{L})^{56}$ &
\end{tabular}




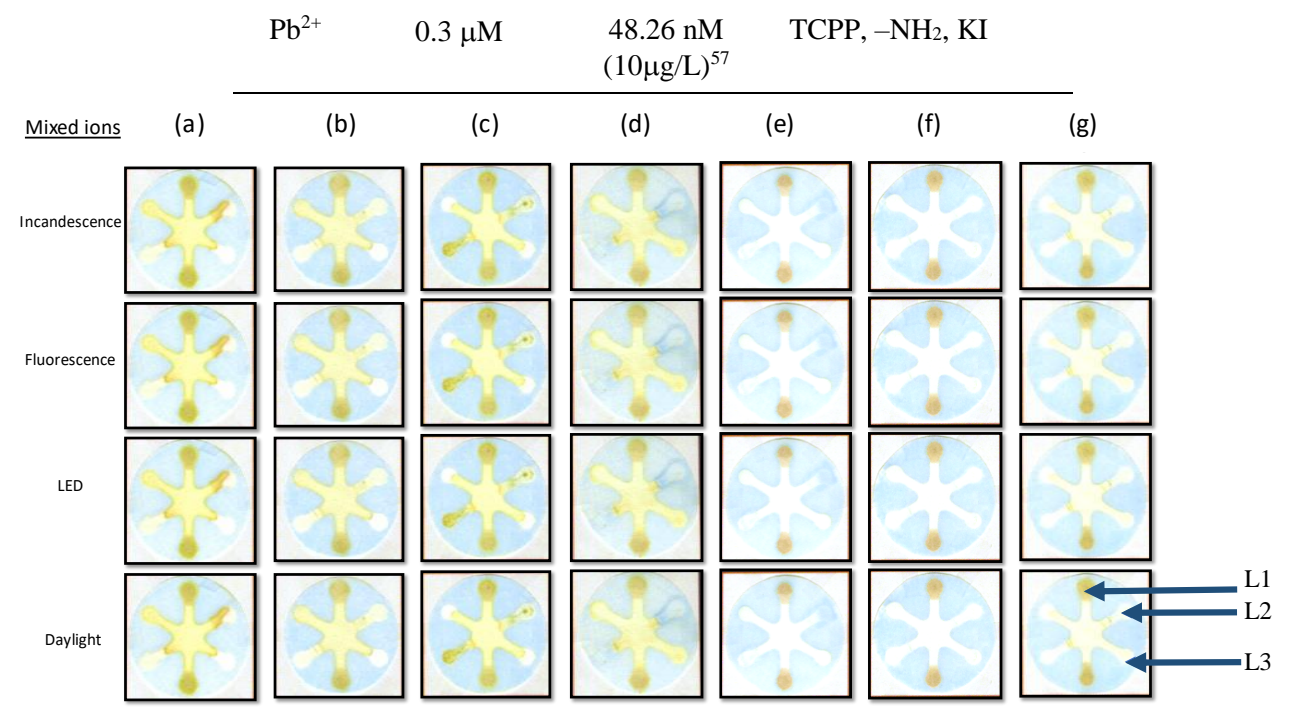

Figure 6: Calibrated images captured under different lighting conditions of $\mathrm{Cu}^{2+}, \mathrm{Cr}^{2+}$ and $\mathrm{Fe}^{3+}$ mixture at different mixing ratios (a-g). The $\left(\mathrm{Cu}^{2+}, \mathrm{Cr}^{2+}, \mathrm{Fe}^{3+}\right)$ mixing ratios are $(\mathrm{a})=(0,1 / 3,2 / 3),(\mathrm{b})=(0,2 / 3,1 / 3),(\mathrm{c})=(1 / 3,0,2 / 3),(\mathrm{d})=(2 / 3,0,1 / 3)$, $(\mathrm{e})=(2 / 3,1 / 3,0),(\mathrm{f})=(1 / 3,2 / 3,0)$, and $(\mathrm{g})=(1 / 3,1 / 3,1 / 3) . \mathrm{L} 1=\mathrm{TCPP}, \mathrm{L} 2=-\mathrm{NH}_{2}$ and $\mathrm{L} 3=\mathrm{MePh}$ indicators.

Real water samples were collected from (i) tap water in the atrium of Centre for Advanced Photonics and Electronics (CAPE), Electrical Engineering Division, (ii) tap water in the Cavendish laboratory canteen (CC), and (iii) Cavendish pond (CP), all in the University of Cambridge. Each of the water samples was filtered through a $0.22 \mu \mathrm{m}$ filter and store at $4^{\circ} \mathrm{C}$. They were then spiked with $0.1 \mathrm{M}$ and $3.58 \mu \mathrm{M} \mathrm{Fe}^{3+}$ (below the level of safe limit), respectively, prior to testing. For both spiked concentrations, the sensor is capable to selectively separate the RGB values of their reactions with respective ligands close to the calibrated values and therefore, cluster the water samples into groups of porphyrin, amine and toluene as illustrated in Figure 7, with little difference among those real water samples. In addition, the sensor is also capable to successfully identify different ion's compositions in a mixture of equal ratio of $\mathrm{Cu}^{2+}, \mathrm{Cr}^{2+}, \mathrm{Fe}^{3+}$ using the analysis technique as tabulated in Tables S-7 and S-8 of the Supporting Information.

(a)

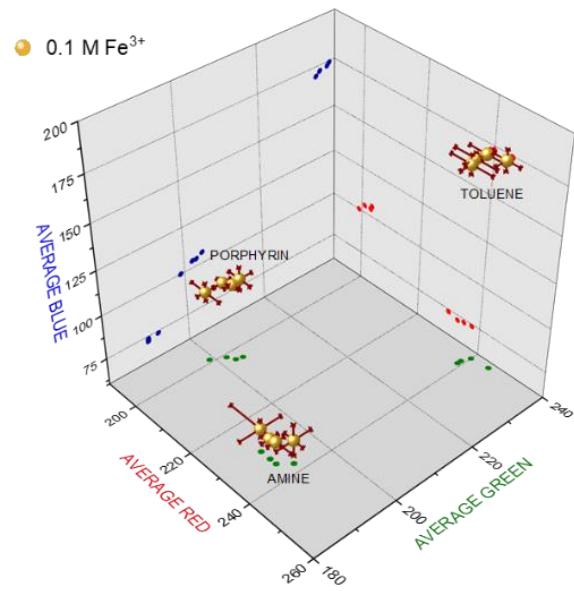

(b)

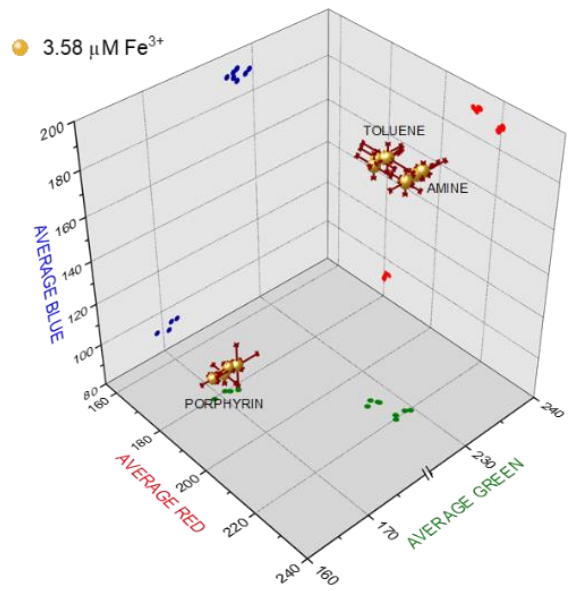

Figure 7: The 3D RGB colour matrix of real water samples spiked with (a) $0.1 \mathrm{M}$ and (b) $3.58 \mu \mathrm{M} \mathrm{Fe}^{3+}$.

\section{CONCLUSIONS}

In conclusion, a facile, reliable and low-cost proof-of-concept platform for sensing single and mixed heavy metals in water has been developed. The sensing technique requires no complicated synthesis, fabrication of devices, or use of expensive instruments. The sensing platform offers high accuracy for cross references and is capable of simultaneous detection and discrimination of different metal ions. To the best of the authors' knowledge, integration of digital image processing with colour calibration technique and paper-based sensor for heavy metals detection has not been reported. Triple-indicator based multidimensional sensing with integration of $\mu \mathrm{PAD}$ has a potential to become a generic approach for cross reference monitoring of $\mathrm{Cr}^{2+}, \mathrm{Fe}^{3+}, \mathrm{Cu}^{2+}$ and $\mathrm{Ni}^{2+}$ with sensitivity below the safe limit concentrations, and a controlled error range. Smartphone technology is being developed as a portable sensing system which includes color calibration and spectrophotometer setup. Smartphone camera and apps can be used in a simple and inexpensive way to carry out the same 
analysis in the field at a very low cost. Further work for better general detection especially in the cases of mixed ions can be done by extending the optical spectrum into infra-red and ultra-violet ranges. 


\section{ASSOCIATED CONTENT}

Supporting Information Available: The following files are available free of charge. Supporting_document.pdf. The document includes the definition and evaluation of the calibration algorithm using Munsell colorchecker as reference, paper selection and fabrication of the paper-based microfluidic sensor, metal-ligand complexes energy gap examined using the spectrophotometer in the UV-visible range, RGB colour profile of the metal ions interaction with multiple ligands at wastewater discharge concentrations, and the study of ion compositions in a mixture.

\section{AUTHOR INFORMATION}

\section{Corresponding Author}

*Email: dpc31@cam.ac.uk. Tel: +44(0) 1223 748352. Fax: +44 (0) 1223748348

\section{AUTHOR CONTRIBUTIONS}

Noorhayati is responsible for all the experimental work, data analysis and writing of the manuscript. Daping Chu proposed the multidimensional colorimetric sensing idea, supervised the work, advised the paper presentation and contents, and participated in the paper writing. All authors have given approval to the final version of the manuscript.

\section{REFERENCES}

1. Fernández-Luqueño, F.; López-Valdez, F.; Gamero-Melo, P.; Luna-Suárez, S.; Aguilera-González, E.N.; Martínez, A.I.; García-Guillermo, M.D.S.; Hernández-Martínez, G.; Herrera-Mendoza, R.; Álvarez-Garza, M.A.; Pérez-Velázquez, I.R. Heavy metal pollution in drinking water - a global risk for human health. African J. of Env. Sci. and Tech. 2013, 7(7), 567584.

2. Verma, N.; Singh, M. Biosensors for heavy metals. Biometals, 2005, 18, 121-129.

3. Liu, X.; Song, Q.; Tang, Y.; Li, W.; Xu, J.; Wu, J.; Wang, F.; Brookes, P.C. Human health risk assessment of heavy metals in soil-vegetable system: A multi-medium analysis. Sci. Total Environ. 2013, 463-464, 530-540.

4. Morton, J.; Havens, N.; Mugweru, A.; Wanekaya, A.K. Detection of trace heavy metal ions using carbon nanotubemodified electrodes. Electroanalysis, 2009, 21, 1597-1603.

5. Nomngongo, P.N.; Ngila, J.C.; Msagati, T.A.M., (2011) Indirect Amperometric Determination of Selected Heavy Metals Based on Horseradish Perodidase Modified Electrodes, in Biosensors - Emerging Materials and Applications, ed. Serra, P.A., InTech, ch. 25, pp. 569-588.

6. Yue, W.; Riehl, B.L.; Pantelic, N.; Schlueter, K.T.; Johnson, J.M.; Wilson, R.A.; Guo, X.; King, E.E. and Heineman, W.R. Anodic Stripping Voltammetry of Heavy Metals on a Metal Catalyst Free Carbon Nanotube Electrode. Electroanalysis, 2012, 24, 1039-1046.

7. Zhao, D.; Guo, X.; Wang, T.; Alvarez, N.; Shanov, V.N.; Heineman, W.R. Simultaneous Detection of Heavy Metals by Anodic Stripping Voltammetry Using Carbon Nanotube Thread. Electroanalysis, 2014, 26, 488-496.

8. Selid, P.D.; Xu, H.; Collins, E.M.; Face-Collins, M.S.; Zhao, J.X. Sensing Mercury for Biomedical and Environmental Monitoring. Sensors, 2009, 9, 5446-5459.

9. Li, M.; Gou, H.; Al-Ogaidi, I.; Wu, N. Nanostructured Sensors for Detection of Heavy Metals: A Review. ACS Sustainable Chem. Eng., 2013, 1, 713-723.

10. Quang, D.T.; Kim, J.S. Fluoro-and Chromogenic Chemodosimeters for Heavy Metal Ion Detection in Solution and Biospecimens. Chem. Rev. 2010, 110, 6280-6301.

11. Awual, M.R.; Hasan, M.M. Colorimetric detection and removal of copper (II) ions from wastewater samples using tailormade composite adsorbent. Sens. Actuators B: Chem. 2015, 206, 692-700.

12. Rakow, N.A.; Suslick, K.S. A colorimetric sensor array for odour visualization. Nature. 2000, 406, 710-713.

13. Askim, J.R.; Mahmoudi, M. \& Suslick, K.S. Optical sensor arrays for chemical sensing: the optoelectronic nose. Chem. Soc. Rev. 2013, 42, 8649-8682.

14. Diehl, K.L.; Anslyn, E.V. Array sensing using optical methods for detection of chemical and biological hazards. Chem. Soc. Rev. 2013, 42, 8596-8611.

15. Anzenbacher Jr, P.; Lubal, P.; Buček, P.; Palacios, M.A.; Kozelkova, M.E. A practical approach to optical cross-reactive sensor arrays. Chem. Soc. Rev. 2010, 39, 3954-3979.

16. Albert, K.J.; Lewis, N.S.; Schauer, C.L.; Sotzing, G.A.; Stitzel, S.E.; Vaid, T.P.; Walt, D.R. Cross-reactive chemical sensor arrays. Chem. Rev. 2000, 100, 2595-2626. 
17. Kreno, L.E.; Leong, K.; Farha, O.K.; Allendorf, M.; Van Duyne, R.P.; Hupp, J.T. Metal-organic framework materials as chemical sensors. Chem. Rev. 2012, 112, 1105-1125.

18. Qian, S.; Lin, H. Colorimetric sensor array for detection and identification of organophosphorus and carbamate pesticides. Anal. Chem. 2015, 87, 5395-5400.

19. Liu, L.; Lin, H. Paper-based colorimetric array test strip for selective and semiquantitative multi-ion analysis: simultaneous detection of $\mathrm{Hg}^{2+}, \mathrm{Ag}^{+}$, and $\mathrm{Cu}^{2+}$. Anal. Chem. 2014, 86, 8829-8834.

20. Selvakumar, K.; Motiei, L.; Margulies, D. Enzyme-artificial enzyme interactions as a means for discriminating among structurally similar isozymes. J. Am. Chem. Soc. 2015, 137, 4892-4895.

21. Liu, Y.; Bonizzoni, M. A supramolecular sensing array for qualitative and quantitative analysis of organophosphates in water. J. Am. Chem. Soc. 2014, 136, 14223-14229.

22. Diaz de Greñu, B.; Moreno, D.; Torroba, T.; Berg, A.; Gunnars, J.; Nilsson, T.; Nyman, R.; Persson, M.; Pettersson, J.; Eklind, I.; Wästerby, P. Fluorescent discrimination between traces of chemical warfare agents and their mimics. J. Am. Chem. Soc. 2014, 136, 4125-4128.

23. Zhang, Z.; Kim, D.S.; Lin, C.Y.; Zhang, H.; Lammer, A.D.; Lynch, V.M.; Popov, I.; Milijanić, O.S.; Anslyn, E.; Sessler, J.L. Expanded porphyrin-anion supramolecular assemblies: environmentally responsive sensors for organic solvents and anions. J. Am. Chem. Soc. 2015, 137, 7769-7774.

24. Chen, K.; Shu, Q.; Schmittel, M. Design strategies for lab-on-a-molecule probes and orthogonal sensing. Chem. Soc. Rev. 2015, 44, 136-160.

25. Schmittel, M.; Lin, H.-W. Quadruple-channel sensing: a molecular sensor with a single type of receptor site for selective and quantitative multi-ion analysis. Angew. Chem. Int. Ed. 2007, 46, 893-896.

26. Ling, Y.; Gao, Z.F.; Zhou, Q.; Li, N.B.; Luo, H.Q. Multidimensional optical sensing platform for detection of heparin and reversible molecular logic gate operation based on the phloxine B/polyethyleneimine system. Anal. Chem. 2015, 87, 15751581.

27. Wu, P.; Miao, L.-N.; Wang, H.-F.; Shao, X.-G.; Yan, X.-P. A multidimensional sensing device for the discrimination of proteins based on manganese-doped $\mathrm{ZnS}$ quantum dots. Angew. Chem. Int. Ed. 2011, 50, 8118-8121.

28. Lee, J.S.; Shin, D.H.; Jun, J.; Jang, J. Multidimensional polypyrrole/iron oxyhydroxide hybrid nanoparticles for chemical nerve gas agent sensing application. ACS Nano. 2013, 7, 10139-10147.

29. Bajaj, A.; Miranda, O.R.; Kim, I.B.; Phillips, R.L.; Jerry, D.J.; Bunz, U.H.; Rotello, V.M. Detection and differentiation of normal, cancerous, and metastatic cells using nanoparticle-polymer sensor arrays. Proc. Nat. Acad. Sci. USA. 2009, 106, 10912-10916.

30. Magri, D.C.; Fava, M.C.; Mallia, C.J. A sodium-enabled 'Pourbaix sensor': a three-input AND logic gate as a 'lab-on-amolecule' for monitoring $\mathrm{Na}^{+}$, $\mathrm{pH}$ and $\mathrm{pE}$. Chem. Commun. 2014, 50, 1009-1011.

31. Lu, Y.; Kong, H.; Wen, F.; Zhang, S.; Zhang, X. Lab-on-graphene: graphene oxide as a triple-channel sensing device for protein discrimination. Chem. Commun. 2013, 49, 81-83.

32. Sang L.J.; Wang, H.-F. Aminophenylboronic-acid-conjugated polyacrylic acid-Mn-doped ZnS quantum dot for highly sensitive discrimination of glycoproteins. Anal. Chem. 2014, 86, 5706-5712.

33. Hagleitner, C.; Hierlemann, A.; Lange, D.; Kummer, A.; Kerness, N.; Brand, O.; Baltes, H. Smart single-chip gas sensor microsystem. Nature. 2001, 414, 293-296.

34. Hierlemann, A.; Gutierrez-Osuna, R. Higher-order chemical sensing. Chem. Rev. 2008, 108, 563-613.

35. Kwon, O.S.; Park, S.J.; Lee, J.S.; Park, E.; Kim, T.; Park, H.-W.; You, S.A.; Yoon, H.; Jang, J. Multidimensional conducting polymer nanotubes for ultrasensitive chemical nerve agent sensing. Nano Lett. 2012, 12, 2797-2802.

36. Huang, Y.; Li, F.; Qin, M.; Jiang, L.; Song, Y. A multi-stopband photonic-crystal microchip for high-performance metalion recognition based on fluorescent detection. Angew. Chem. Int. Ed. 2013, 52, 7296-7299.

37. Huang, Y.; Li, F.; Ye, C.; Qin, M.; Ran, W.; Song, Y. A photochromic sensor microchip for high-performance multiplex metal ions detection. Sci. Rep. 2015, 5, 9724.

38. Leng, Y.; Qian, S.; Wang, Y.; Lu, C.; Ji, X.; Lu, Z.; Lin, H. Single-indicator-based Multidimensional Sensing: Detection and Identification of Heavy Metal Ions and Understanding the Foundations from Experiment to Simulation. Sci Rep. 2016, 6, 25354. 
39. Xu, S.; Lu, X.; Yao, C.; Huang, F.; Jiang, H.; Hua, W.; Na, N.; Liu, H.; Ouyang, J. A visual sensor array for pattern recognition analysis of proteins using novel blue-emitting fluorescent gold nanoclusters. Anal Chem. 2014, 86, 1163411639.

40. Pan, L.; Sun, S.; Zhang, A.; Jiang, K.; Zhang, L.; Dong, C.; Huang, Q.; Wu, A.; Lin, H. Truly fluorescent excitationdependent carbon dots and their applications in multicolour cellular imaging and multidimensional sensing. Adv. Mater. 2015, 27, 7782-7787.

41. Leng, Y.; Li. Y.; Gong, A.; Shen, Z.; Chen, L.; Wu, A. Colorimetric response of dithizone product and hexadecyl trimethyl ammonium bromide modified gold nanoparticle dispersion to 10 types of heavy metal ions: understanding the involved molecules from experiment to simulation. Langmuir 2013, 29, 7591-7599.

42. Lou, T.; Chen, Z.; Wang, Y.; Chen, L. Blue-to-red colorimetric sensing strategy for $\mathrm{Hg}^{2+}$ and $\mathrm{Ag}^{2+}$ via redox-regulated surface chemistry of gold nanoparticles. ACS Appl. Mater. Interfaces. 2011, 3 (5), 1568-1573.

43. Chen, L.; Li, J.; Chen, L. Colorimetric detection of mercury species based on functionalized gold nanoparticles. ACS Appl. Mater. Interfaces. 2014, 6(18), 15897-15904.

44. Chen, L.; Fu, X.; Lu, W.; Chen, L. Highly sensitive and selection colorimetric sensing of $\mathrm{Hg}^{2+}$ based on the morphology transition of silver nanoprisms. ACS Appl. Mater. Interfaces. 2013, 5(2), 284-290.

45. Ding, Y.; Wang, S.; Li, J.; Chen, L. Nanomaterial-based optical sensors for mercury ions. Trends Analyt. Chem. 2016, 82, 175-190.

46. Li, Y.; Chen, Y.; Yu, H.; Tian, L.; Wang, Z. Portable and smart devices for monitoring heavy metal ions integrated with nanomaterials. Trends Analyt. Chem. 2018, 98, 190-200.

47. Yamada, K.; Suzuki, K.; Citterio, D. Text-displaying colorimetric paper-based analytical device. ACS Sens. 2017, 2(8), $1247-1254$

48. Chan, H. N.; Shu, Y.; Xiong, B.; Chen, Y.; Chen, Y.; Tian, Q.; Michael, S. A.; Shen, B.; Wu, H. Simple, cost-effective 3D printed microfluidic components for disposable, point-of-care colorimetric analysis. ACS Sens., 2016, 1 (3), 227-234.

49. Hossain, S.Z.; Brennan, J.D. $\beta$-Galactosidase-based colorimetric paper sensor for determination of heavy metals. Anal. Chem. 2011, 83(22), 8772-8778.

50. Wang, H.; Li, Y.-J.; Wei, J.-F.; Xu, J.-R.; Wang, Y.-H.; Zheng, G.X. Paper-based three-dimensional microfluidic device for monitoring of heavy metals with a camera cell phone. Anal. Bioanal. Chem. 2014, 406(12), 2799-2807.

51. Sun, H.; Li, W.; Dong, Z.-Z.; Hu, C.; Leung, C-H.; Ma, D.-L.; Ren, K. A suspending-droplet mode paper-based microfluidic platform for low-cost, rapid, and convenient detection of lead(II) ions in liquid solution. Biosens. \& Bioelectron. 2018, 99 , 361-367.

52. Li, B.; Fu, L.; Zhang, W.; Feng, W.; Chen, L. Portable paper-based device for quantitative colorimetric assays relying on light reflectance principle. Electrophoresis. 2014, 35, 1152-1159.

53. Chaiyo, S.; Apiluk, A.; Siangproh, W.; Chailapakul, O. High sensitivity and specificity simultaneous determination of lead, cadmium and copper using $\mu \mathrm{PAD}$ with dual electrochemical and colorimetric detection. Sens. Actuators B. Chem. 2016, $233,540-549$.

54. Li, M.; Cao, R.; N, A.; Guan, L.; Zhang, X.; Shen, W. "Periodic-Table-Style" paper device for monitoring heavy metals in water. Anal. Chem. 2015, 87, 2555-2559.

55. Meelapsom, R.; Jarujamrus, P,; Amatatongchai, M.; Chairam, S.; Kulsing, C.; Shen, W. Chromatic analysis by monitoring unmodified silver nanoparticles reduction on double layer microfluidic paper-based analytical devices for selective and sensitive determination of mercury(II). Talanta. 2016, 155, 193-201.

56. USEPA, United Stated Environmental Protection Agency (2009). National Primary Drinking Water Regulations. Retrieved from https://www.epa.gov/ground-water-and-drinking-water/national-primary-drinking-water-regulations\#Inorganic (Verified August 14, 2018).

57. WHO, World Health Organization (2011). Guidelines for drinking-water quality, fourth edition. Retrieved from http://apps.who.int/iris/bitstream/handle/10665/44584/9789241548151_eng.pdf;jsessionid=FCE6CFF1FA1B6C2BE68E5 78EC3D894D9? sequence=1 (verified August 14, 2018).

58. de Tarso Garcia, P.; Cardoso, T.M.G.; Garcia, C.D.; Carrilho, E.; Coltro, W.K.T. A handheld stamping process to fabricate microfluidic paper-based analytical devices with chemically modified surface for clinical assays. RSC Adv., 2014, 4, 37637-37644. 
59. Colour Checker Chart. (2012) [Online]. Available: http://www.mathworks.com/matlabcentral/fileexchange/38236-colorchecker-chart

60. Bracher, P.J.; Gupta, M.; Whitesides, G.M. Shaped Films of Ionotropic Hydrogels Fabricated Using Templates of Patterned Paper. Adv Mater. 2009, 21, 445-450.

61. Ngo, Y.H.; Li, D.; Simon, G.P.; Garnier, G. Gold Nanoparticle-Paper as a Three-Dimensional Surface Enhanced Raman Scattering Substrate. Langmuir ACS J Surf Colloids. 2012, 28, 8782-8790.

62. Bracher, P.J.; Gupta, M.; Whitesides, G.M. Patterned paper as a template for the delivery of reactants in the fabrication of planar materials. Soft Matter. 2010, 6, 4303-4309.

63. Volicer, B., Tello, S. d-Metal Complexes. 1998. Retrieved from http://faculty.uml.edu/ndeluca/84.334/topics/topic6.htm

64. Kozak, C. M. Chemistry 3211 - Coordination Chemistry Part 3. Ligand Field and Molecular Orbital Theory. Retrieved from http://www.chem.mun.ca/homes/cmkhome/Chemistry\%203211\%20Pt3.pdf. 


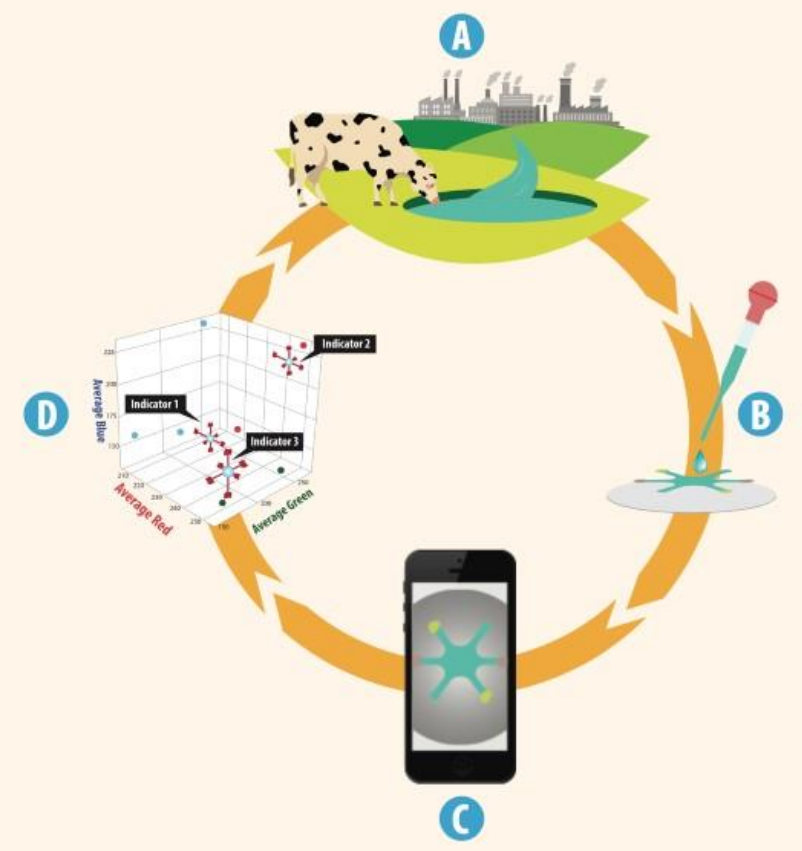

"for TOC only" 